\title{
Comparative Analysis of Long Non-Coding RNA and mRNA Expression Provides Insights into Adaptation to Hypoxia in Tibetan Sheep
}

\section{Jianbin Liu ( $\square$ liujianbin@caas.cn )}

CAAS Lanzhou Institute of Animal Husbandry and Veterinary Medicine: Chinese Academy of Agricultural Sciences Lanzhou Institute of Husbandry and Pharmaceutical Sciences https://orcid.org/0000-0001-6550-9236

\section{Chao Yuan}

CAAS Lanzhou Institute of Animal Husbandry and Veterinary Medicine: Chinese Academy of Agricultural Sciences Lanzhou Institute of Husbandry and Pharmaceutical Sciences

\section{Zengkui Lu}

CAAS Lanzhou Institute of Animal Husbandry and Veterinary Medicine: Chinese Academy of Agricultural Sciences Lanzhou Institute of Husbandry and Pharmaceutical Sciences

\section{Deqing Zhuoga}

Institute of livestock, tibet academy of agriculture and animal science

\section{Tingting Guo}

CAAS LIHPS: Chinese Academy of Agricultural Sciences Lanzhou Institute of Husbandry and Pharmaceutical

\section{Sciences}

\section{Jianbo Zhang}

CAAS LIHPS: Chinese Academy of Agricultural Sciences Lanzhou Institute of Husbandry and Pharmaceutical Sciences

\section{Dan Zhang}

CAAS LIHPS: Chinese Academy of Agricultural Sciences Lanzhou Institute of Husbandry and Pharmaceutical Sciences

\section{Zhaxi Zhuoma}

agricultural and animal husbandry technology extension service cenyer of haixi prefecture

\section{Hao Zhang}

pizhou agricultural and rural bureau of jiangsu province

\section{Bohui Yang}

CAAS LIHPS: Chinese Academy of Agricultural Sciences Lanzhou Institute of Husbandry and Pharmaceutical

\section{Sciences}

\section{Research article}

Keywords: Tibetan sheep, transcriptome, IncRNAs, mRNAs, hypoxia

Posted Date: October 8th, 2020

DOI: https://doi.org/10.21203/rs.3.rs-77480/v1 
License: (a) (1) This work is licensed under a Creative Commons Attribution 4.0 International License. Read Full License 


\section{Abstract}

Background: Tibetan sheep have lived on the Tibetan Plateau for thousands of years and they have a good adaptability to the hypoxic environment and strong disease resistance. However, the molecular mechanism of the Tibetan sheep adapting to this extreme environment, especially the role of genetic regulation is still unknown. Emerging evidence suggests that long non-coding RNAs (IncRNAs) participate in the regulation of a diverse range of biological processes. To explore the potential IncRNAs involved in Tibetan sheep adapting to high altitude hypoxia environment, we analyzed the expression profile of IncRNAs and mRNAs in liver and lung tissue of sheep based on the comparative transcriptome analysis between four Tibetan sheep populations (high altitude) and Hu sheep (low altitude).

Results: A total of 7848 differentially expressed (DE) IncRNAs transcripts and 22971 DE mRNAs transcripts were detected by pairwise comparison. The expression patterns of selected mRNAs and IncRNAs were validated by qRTPCR and the results correlated well with the transcriptome data. Moreover, the functional annotation analysis based on the Gene Ontology (GO) and Kyoto encyclopedia of genes and genomes (KEGG) databases showed that DE mRNAs and the target genes of the IncRNAs were significantly enriched in organ morphogenesis, response to stimulus, heme binding, immune system, arginine and proline metabolism, and fatty acid biosynthesis. The prediction of mRNA-mRNA and IncRNA-mRNA interaction networks further revealed transcripts potentially involved in adaptation to high altitude hypoxia, the hub genes that DDX24, PDCD11, EIF4A3, NDUFA11, SART1, PRPF8 and TCONS_00306477, TCONS_00306029, TCONS_00139593, TCONS_00293272, TCONS_00313398 were selected. Additionally, a set of target genes, PIK3R1, IGF1R, FZD6, IFNB2, ATF3, MB, CYP2B4, PSMD13, and TGFB1 were also identified as candidate genes associated with high altitude hypoxia adaptation.

Conclusions: A collection of aberrantly expressed IncRNA, a set of target genes and biological pathways known to be relevant for altitude adaptation were identified by comparative transcriptome analysis between Tibetan sheep and Hu sheep. Our results first identified the characterization and expression profile of IncRNAs between Tibetan sheep and Hu sheep and provides insights into the genetic regulation mechanisms for Tibetan sheep adaptation to high altitude hypoxia environments.

\section{Background}

Tibetan sheep is one of China's three primitive sheep populations, mainly distributed among the Qinghai-Tibet Plateau, with Qinghai, Tibet and Gannan in Gansu [1, 2]. The combined effects of cold and hypoxia in high altitude areas pose severe physiological challenges for Tibetan sheep. The decrease in oxygen partial pressure at high altitude reduces the oxygen supply to the cells of the respiratory tissue [3]. Decreased tissue oxygenation will severely limit aerobic metabolism and inhibit the ability to produce heat, thereby resisting the effects of the decrease in ambient temperature that accompanies an increase in altitude on the body $[4,5]$. The cold and hypoxic conditions at high altitudes have seriously affected the metabolic needs of Tibetan sheep [6]. Therefore, analyzing how Tibetan sheep deal with hypoxia and cold helps to analyze the adaptive evolution process. To elucidate the molecular genetic basis of the Tibetan sheep adapting to high cold and hypoxia is the central goal of evolutionary genetics.

Oxygen is the key substance for the animal body to carry out metabolism and maintain life, and it is the first need for life activities [7]. The breathing oxygen is converted into available oxygen in the animal, called blood oxygen. The blood oxygen carried by the blood inputs energy to the whole body, and the delivery amount of blood oxygen is closely related to the working state of the heart and brain. The stronger the heart's blood pumping ability, the higher the blood oxygen content; the strongly coronary blood transfusion ability of the heart, the higher the concentration 
of blood oxygen delivered to the heart and brain and whole body, the better operating state of important animal organs [8]. Medically, an area with an altitude of more than 3,000 meters is called a plateau. The impact of the plateau environment on animal organisms involves many aspects, such as atmospheric geography, geochemistry, ecology, and other factors. Factors such as low atmospheric pressure, low oxygen, low temperature, low humidity, solar radiation, airflow, rainfall, light, wind, and snow often act on animal organisms. Among them, the impact of plateau hypoxia has attracted wide attention to scholars because of its most significant impact $[3,9]$.

In terms of molecular research on hypoxia adaptation, studies have shown that hypoxia inducible factor-1 (HIF-1) is one of the genes being selected by the high altitude and low oxygen environment $[10,11]$. The HIF-1a subunit is encoded by the HIF-1A gene, mainly regulated by oxygen concentration and determines the level of HIF-1a activity [12]. The expression level of HIF-2a mRNA in Tibetan sheep is higher in lung, liver, kidney, and myocardial tissues than that in low altitude sheep. It can quickly induce the expression of its downstream factors VEGF (Vascular endothelial growth factor), EPO (Erythropoietin), lung surfactant, strengthen the lipid oxidative phosphorylation reaction, and thereby enhance the lung ventilation capacity, heart pumping function, kidney EPO synthesis and liver metabolic reaction to meet the oxygen and energy required for body activities. The expression level of STAT3 mRNA in Tibetan sheep is higher in lung, liver, and myocardial tissues than that in low altitude sheep [13]. It indicates that the hypoxia environment induces high expression of STAT3 protein to promote the generation of activated STAT3, which can effectively regulate the transcription of VEGF, COX-2, MnSOD, UCP1, HIF-1a and its downstream target genes, thereby enhancing the ventilation capacity of Tibetan sheep lungs, hypoxic adaptability of heart pumping function and energy metabolism [14].

At present, a number of scientists have studied the mechanism of hypoxic adaptation in the Tibetan Plateau at the genetic level, but the molecular mechanism of Tibetan sheep adapting to this extreme environment, especially the role of genetic regulation is still unknown. Long non-coding RNAs (IncRNAs) are transcripts longer than 200 nucleotides that can regulate mRNA expression of both posttranscriptional and transcriptional levels [15]. There is limited literature on the detailed functional roles of IncRNAs in high altitude adaptation of Tibet [16-18]. The role of IncRNA in Tibetan sheep's hypoxic adaptation has not been reported yet. The latest research progress of highthroughput sequence technology has opened up a new path to exploring the molecular genetic basis of adaptive physiological traits. Transcriptome sequencing (mRNA and IncRNA) can not only find important genes that cope with physiological challenges, but also provide an in-depth understanding of the role of transcription regulation in adapting to evolutionary variation.

In this study, the genetic expression and regulation mechanisms of different populations and tissues in the Tibetan sheep under different altitude conditions were investigated based on the comparative transcriptome analysis. Functional genes associated with high altitude hypoxia adaptation in Tibetan sheep were found by the perspective of mRNA, IncRNA and their co-expression networks analysis.

\section{Results}

\section{The physiological and biochemical indices of five sheep populations from different altitude region}

This work carried out a comparative study on the lung tissue structure, blood gas indices, haematological and serum biochemical indices of Tibetan sheep and Hu sheep at different altitudes (Tab. S1 and Fig. 1). The lung of Tibetan sheep at high altitude regions has typical characteristics in tissue structure. Compared with Hu sheep from 
low-altitude regions, the terminal bronchioles of Tibetan sheep showed larger diameter, the thickness of the alveolar septum increased, and the number of alveoli and blood vessels has increased per unit area $(P<0.05)$. These changes in tissue structure are conducive to accelerating blood oxygen transport and increasing alveolar ventilation, increasing Tibetan sheep's lung blood flow and the lung gas exchange rate of Tibetan sheep in a hypoxic

environment to a certain extent. This is one of the bases of Tibetan sheep to adapt to high altitude environment [19, 20]. Furthermore, the measurement results from blood gas indices of Tibetan sheep at different altitudes found that oxygen partial pressure $\left(\mathrm{PO}_{2}\right)$, oxygen saturation $\left(\mathrm{O}_{2} \mathrm{~S}\right)$, and standard base excess (SBE) decreased significantly as the altitude increased $(P<0.05)$. Related studies have shown that Tibetan sheep can reduce tissue oxygen demand and cell metabolism levels through specific physiological changes, and adapt to the plateau hypoxia environment at the molecular level by regulating hypoxia inducible factor [13]

In addition, haematological indices such as red blood cell count (RBC), white blood cell count (WBC), haemoglobin contents (HGB), and red blood cell distribution width coefficient of variation (RDW-CV) were measured, as well as blood biochemical indices such as alanine aminotransferase (ALT), aspartate aminotransferase (AST), total protein (TP), and cholinesterase (PChE). The results showed that the HGB, RBC, WBC, and other indices of Tibetan sheep at high altitude were significantly higher than those of low-altitude Hu sheep $(P<0.05)$, and the RDW-CV became smaller. The reason for the difference might be due to the high cold and hypoxic factors, especially the value of HGB increases from the increase of altitude. Under low $\mathrm{PO}_{2}$, HGB dissociates from oxygen to provide the body of the oxygen needed for energy metabolism to better adapt to the low oxygen environment. The measurement results from serum biochemical indices showed that AST, TP, and others increased with altitude $(P<0.05)$, while ALT and PChE decreased. In particular, the values of TP increased to the altitude, which is helpful to enhance the immune function of sheep and adapt to the high-altitude ecological environment.

\section{Identification of IncRNAs and mRNAs in sheep liver and lung tissue}

The Illumina sequencing of 30 sample's cDNA libraries derived from five sheep populations yielded a total of 187.28 Gb and $190.63 \mathrm{~Gb}$ clean data for liver and lung tissue, respectively. At least $78.05 \%$ of the clean reads from each sample was mapped to the sheep reference genome (Oar_v3.1, ftp://ftp.ensembl.org/pub/release78/fasta/ovis_aries/), of which more than 78.52\% were uniquely mapped (Tab. S2).

For liver samples, a total of 6,249 IncRNAs was identified after coding potential filters using CNCl, CPC, CPAT and Pfam-scan software, 20,078 mRNAs and 2,728 novel transcripts were identified. In addition, a total of 1,798 IncRNAs, 13,319 mRNAs and 750 novel transcripts were identified from lung samples (Tab. S3). The exon number, transcript length, and ORF length of IncRNAs and mRNAs were calculated and graphed, as shown in Fig. 2 and Fig. S1. A majority of IncRNAs comprised two or three exons, whereas mRNAs contained a broad range of exon numbers from two to thirty. The transcript length and ORF length of IncRNAs were significantly shorter than those of mRNAs. Moreover, the expression levels of mRNAs and IncRNAs were further analyzed using FPKM. The mRNA transcript levels were higher than those of IncRNAs in both liver (Fig. S1) and lung (Fig. 2) tissue.

\section{DE IncRNA and mRNA between Hu sheep and Tibetan sheep}

Pearson's correlation coefficient $\left(r^{2}\right)$ was used as the evaluation indicator to detect inter-individual relatedness of the samples. The correlation coefficient tends to 1 between samples of the same group, thus indicating that it is reasonable to perform further data analyses (Fig. S2). Based on a fold change of $\geq 2$ and false discovery rate of < 
0.05, in total, 7,848 DE IncRNA transcripts and 22,971 DE mRNA transcripts were detected in all groups by pairwise comparison (Tab. S4)

Furthermore, we focused on the analysis of the pairwise comparison between Tibetan sheep and Hu sheep (AW vs HS, HB vs HS, GJ vs HS, WT vs HS). The up and down regulation of DE genes in each comparison is shown in Fig. 3 and Tab. S5. A circus figure of chromosome distribution of the DE genes is shown in Fig. S3. We found that most of the DE genes were enriched on chromosomes 1, 2,3, and chromosome $X$.

The analysis of common DE genes between liver and lung by pairwise comparison found 3 common DE IncRNAs 316 common DE mRNAs (Fig. 4A and B). Further analysis of common differentially expressed genes (DEGs) among Tibetan sheep and Hu sheep groups, 2 common DE IncRNAs and 99 common DE mRNAs in liver were detected by pairwise comparison (Fig. 4C and D). Additionally, 1 common DE IncRNA transcripts and 63 common DE mRNA transcripts were detected in lung (Fig. 4E and F).

\section{Functional Annotation of DE mRNAs and the target genes of DE IncRNAs}

To gain more insights into the DE mRNAs and the target genes of DE LncRNAs, the Nr, COG, Swiss-Prot, GO and KEGG databases were used to annotate DE mRNAs. The overall functional annotation of DE mRNAs in pairwise comparison (AW vs HS, HB vs HS, GJ vs HS, WT vs HS) is described in Tab. S6. As IncRNAs could exert effects on cis-acting or trans-acting target genes, we predicted 1,739 target genes of DE IncRNAs that might be potentially involved in the adaptation to high altitudes based on the cis and trans RNA-RNA interaction principle. In total, 218 and 197 target genes were differentially expressed and annotated from liver and lung tissue by pairwise comparison (Tab. S7).

To elucidate the functions of DE mRNAs, GO enrichment analysis was performed using topGO to search the most significant GO term of DE mRNAs. The most enriched GO terms of the DE mRNAs in each comparison are shown in Tab. S7. All of the DE mRNAs were assigned to GO terms of biological processes, cellular components, and molecular function. Moreover, response to stimulus, tissue development, skeletal system development, response to stress, regulation of signal transduction, organ development, antioxidant activity, calcium ion binding, heme binding, and lipid antigen binding were identified as significantly enriched GO terms. According to the KEGG analysis, the most enriched pathway to DE mRNAs $(P<0.05)$ is predominantly associated with amino acid metabolism, lipid metabolism and immune system, such as arginine and proline metabolism, hematopoietic cell lineage, fatty acid biosynthesis, glutathione metabolism, and biosynthesis of unsaturated fatty acids.

\section{LncRNA-mRNA co-expression networks construction}

In order to understand the effects of IncRNAs on the regulation of the target genes, we constructed mRNA-IncRNA regulatory network. Firstly, we selected the target genes of DE IncRNAs to construct functional networks by referring to the STRING database, with each gene corresponding to a node. Two genes were connected by an edge, indicating a correlation between mRNA-mRNA. Next, DE IncRNAs and their corresponding target genes were used to construct the IncRNA-mRNAs interaction network. Then, the mRNA-mRNA and IncRNA-mRNAs network were merged (Fig. S4). Within the network analysis, we focused on the top 10 DE mRNAs with the highest degree and IncRNAs that interacted with more target genes (Tab. S8), constituting probably the core of the network. The results implied that DE mRNAs DDX24, PDCD11, EIF4A3, NDUFA11, SART1, PRPF8 and DE IncRNAs TCONS_00306477, TCONS_00306029, TCONS_00139593, TCONS_00293272, and TCONS_00313398 might play key roles in 
adaptation to hypoxia. Although these IncRNAs requires further experimental validation, this information might be helpful to explore the potential mechanisms involved in the adaptation to hypoxia at high altitudes.

\section{The candidate genes screen for the adaptation to hypoxia at high altitudes}

A set of candidate genes that were putatively associated with hypoxia responses to high altitudes were screened from the target genes of DE IncRNAs. For a detailed description of the relevant functions and pathway to candidate genes see Table 1. Among them, three (PIK3R1, IGF1R and PDK1) were located in the classical HIF-1 pathway, which played a central role in regulating cellular responses to hypoxia [21-23]; five were found in the corresponding downstream vascular endothelial growth factor (VEGF, FZD4 and IFNB2) and glycolysis/gluconeogenesis pathways (ATF3, PPCK1 and PFKFB2). The dysregulation of genes in these relevant pathways indicated that hypoxia-induced factors, angiogenesis, and glycolysis metabolism are the most important factors that allowed sheep to manage extreme hypoxic environmental pressure. We also found six genes $(M B, C Y P 2 C 31, C Y P 2 B 4, C Y P 2 B 5, C Y P 1 A 1$, and $C Y C S$ ) were functionally involved in oxygen binding, oxygen transport, and heme binding. In addition, eight candidate genes (MMP14 [24], TUBB4B [25], PSMD13 [26], COL3A1, COL1A2 [27], DSG3 [28, 29], ATP6 [30] and TGFB1 [22] were also identified as candidate genes associated with high altitude adaptation by previous functional studies. These finding indicated that the relative genes might have played a key role in Tibetan sheep to respond to extreme hypoxic environments.

Moreover, we found the GO terms of the target genes were primarily associated with metabolic processes (amino acid, lipid, and fatty acid), regulation of immune system process, immune response, biological regulation, response to stress and response to stimulus (Tab. S7). These functional terms are biologically relevant to the plateau adaptations because they are involved in energy metabolism, immune function, oxidation reaction, and stress response, which are important regulating factors of Tibetan sheep response to extreme hypoxic environments.

\section{Validation of DE mRNAs and IncRNAs by qRT-PCR}

To evaluate the reliability of RNA sequencing, 7 DE IncRNAs, 13 target genes, and 20 DE mRNAs were selected and validated by qRT-PCR from different sheep groups. All levels of DE IncRNAs and mRNAs were consistent with the RNA-seq results, indicating that the RNA-seq data were reliable (Tab. S9). The result of qRT-PCR and RNA-seq for the common DE IncRNA TCONS_00139593 and TCONS_00332125 in liver and TCONS_00377466 in lung are shown in Fig. 5. Additionally, the confirmed results of $3 \mathrm{DE}$ mRNAs that were enriched in heme binging term (PTGS2 and LOC101107056) and HIF-1 pathway (TFF3) are also shown in Fig. 5.

\section{Discussion}

\section{Comparison of physiological and biochemical indices}

At present, the research on the adaptability of Tibetan sheep to hypoxia at high altitude has made important progress in histology, morphology, physiology, and anatomy [31-34]. Studies suggest that compared to Tan sheep living at low altitude areas, Tibetan sheep have developed a cerebral arterial system, the main arteries are thicker in diameter, and the collateral branches in the cerebral arteries are developed and stretched longer. There are many small arteries, and this feature is conducive to effective blood supply to the brain tissue and the regulation of cerebral arterial blood pressure [35]. This might be one of the anatomical characteristics of Tibetan sheep aiding in adapting to high altitude hypoxia environment. Anatomical studies on the vascular system of other tissues and 
organs of Tibetan sheep have similar results. For example, compared to small-tailed Han sheep, Tibetan sheep have more capillaries in the alveolar septum, and they are mostly open, which also increases with altitude. The alveolar septum is thick, indicating that the alveolar septum is rich in capillaries and elastic fibers. These structural features are conducive to increasing alveolar ventilation, increasing pulmonary blood flow, accelerating blood oxygen transport, and improving lung gas exchange rate in a hypoxic environment. Compared to low-altitude sheep, Tibetan sheep have more red blood cells and higher hematocrit and hemoglobin content. Under low oxygen environment, Tibetan sheep mainly adapt to the low oxygen environment by increasing the hemoglobin content of the blood [36].

In this study, we first examined the haematological changes and serum biochemical parameters in four Tibetan sheep and a Hu sheep population. In agreement with previous reports, the haematological parameters, serum biochemical parameters, the blood gas indices and the morphology of lung tissues showed significant changes between Tibetan sheep (high altitude) and Hu sheep (low altitude). The haematological parameters including RBC, WBC, HGB, HCT, MCV, and PLT became significantly higher as the altitude increased $(P<0.05)$. The biochemical parameters including AST, TP, ALB, GLO, ALP, and LDH significantly increased with increasing altitude, while the ALT and $\mathrm{PCHE}$ decreased from increasing altitude. Moreover, the blood gas indices including $P \mathrm{CO}_{2}, P \mathrm{O}_{2}, \mathrm{O}_{2} \mathrm{~S}, \mathrm{SBC}, \mathrm{TCO}$, and SBE all significantly decreased with increasing altitude. Additionally, the morphology of lung tissue was observed and we found that the terminal bronchioles, the number of alveolar counted per unit area, the alveolar septum thickness and the number of vessels per unit area significantly increased with increasing altitude.

\section{Analysis of IncRNAs and their target genes}

Owing to the key roles of IncRNAs in many important biological processes, these are currently of particular interest $[37,38]$. The rapid development of high throughput sequencing methods had led to the discovery of thousands of IncRNAs in recent years. The studies have reported that the IncRNAs involved in primary wool follicle induction in carpet wool sheep [39], sheep fat-tail development [40], sheep skeletal muscle development [41], prolificacy in Hu sheep [42] and sheep testicular maturation [39,43] with high throughput sequencing technology. But expression and function of IncRNAs in Tibetan sheep adapting to high altitude hypoxia are still unclear. To provide some insights into the biological functions of IncRNAs in Tibetan sheep adaption to high altitude hypoxia, a comprehensive analysis of IncRNA and mRNA profiling data from Tibetan sheep and Hu sheep, together with data from a public database was performed. We identified the core IncRNAs and their target genes, and validated their expression by qRT-PCR. Overall, our work uncovered an interlaced transcripts network that is involved in high altitude hypoxia environment.

By the analysis of common DE genes among Tibetan sheep and Hu sheep groups, 2 common DE IncRNAs TCONS_00139593 and TCONS_00332125 in liver and 1 common DE IncRNA TCONS_00377466 in lung were found. Moreover, the IncRNA-mRNA interaction network of liver sample showed that TCONS_00306477, TCONS_00306029, TCONS_00029720, TCONS_00145870, TCONS_00139593, TCONS_00380986, TCONS_00309307, TCONS_00225957,TCONS_00321529, and TCONS_00100469 interacted with more target genes and suggested as hub genes that related to high altitude hypoxia adaptation; the IncRNA-mRNA interaction network in lung sample showed that TCONS_00293272, TCONS_00313398,TCONS_00344932, TCONS_00078812, TCONS_00352306, TCONS_00380999, TCONS_00088235, TCONS_00467816, TCONS_00078180, and TCONS_00315164 interacted with more target genes and suggested as hub genes.

For the research of candidate genes that are associated with hypoxia responses at high altitudes, an early research reported genome-wide scans that revealed positive selection in several regions that contained genes whose products are likely to be involved in high altitude adaptation [22]. Finally, a set of 247 functional candidate genes 
were identified. The functional candidate genes categories included detection of oxygen (GO:0003032), NO metabolic process (GO:0046209), oxygen sensor activity (GO:0019826), oxygen binding (GO:0019825), oxygen transport (GO:0015671), oxygen transporter activity(GO:0005344), response to hypoxia (GO: 0001666), response to oxygen levels (GO:0070482), Vasodilation (GO:0042311), and hypoxia response via HIF activation (P00030) in panther pathway. In this study, we found that the target genes including MB, PIK3R1, CYP1A1, MMP14, and TGFB1 belong to the list of 247 hypoxia genes. Myoglobin, encoded by $M B$, is a haemoprotein present in cardiac, skeletal and smooth muscle and serves as a reserve supply of oxygen and facilitates the movement of molecular oxygen from the cell membrane to mitochondria [44]. The study has demonstrated that PIK3R1 involved in the HIF-1a signaling pathway plays a critical role in mediating adipose tissue insulin sensitivity [45]. Previous study shows CYP1A1 transcriptional activation was significantly decreased upon $P C B 126$ stimulation under conditions of hypoxia. Additionally, hypoxia pre-treatment reduced $P C B 126$ induced AhR binding to $C Y P 1$ target gene promoters [46]. Moore research showed that MMP14 is upregulated in hypoxic conditions and that this occurs by the interaction of HIF-1a and the MMP14 gene promoter region [47]. Chen et al suggested that TGF-b1 encoded by TGFB1 decreases hypoxia-reoxygenation injury and attenuates alterations in NOS and PKB phosphorylation in myocytes exposed to hypoxia-reoxygenation [48].

Yang et al [49] generated whole-genome sequences from 77 native sheep and detected a novel set of candidate genes as well as pathways and GO categories that were putatively associated with hypoxia responses at high altitudes. Specifically included several positively selected genes within or regulating the HIF-1 pathway, the VEGF pathway, the VSMC pathway, and glycolysis and lipid for energy metabolism. The network of relevant pathways indicated that hypoxia-induced factors, angiogenesis, vasodilatation and glycolysis metabolism were the most important factors that allowed sheep to manage extreme hypoxic environmental pressure. Seven sheep breeds representing both highland and lowland breeds from different areas of China were genotyped for a genome-wide collection of single-nucleotide polymorphisms (SNPs) [50]. Then detected selection events spanning genes were involved in angiogenesis, energy production and erythropoiesis played a crucial role in hypoxia adaption. Here, we found the target genes that PIK3R1, IGF1R and PDK1 in the classical HIF-1 pathway and FZD4, IFNB2, ATF3, PPCK1, $P F K F B 2$ in the corresponding downstream VEGF and glycolysis/gluconeogenesis pathways. Hypoxia regulates IGF1 expression through HIF-1a, and the inhibition of HIF-1a or IGF1R decreased CD133- and Oct4-positive GRPs under hypoxia [51]. Mora et al found that the $P D K 1$ signalling network plays an important role in regulating cardiac viability and preventing heart failure, the deficiency of $P D K 1$ in cardiac muscle results in heart failure and increased sensitivity to hypoxia [52]. ATF3 is a stress-induced transcription factor that plays important roles in regulating immune and metabolic homeostasis. Overwhelming evidence confirms that the ATF3 gene is activated in many tissues by a variety of stress signals, including proinflammatory cytokines, ischemia and hypoxia [53]. Parra et al found that the mRNA levels of glycolytic markers HK2, PFKFB2 and GLUT1 increased accordance with a metabolic shift towards non-mitochondrial ATP generation during hypoxia [54]. The VEGF pathway downstream of HIF-1 and glycolysis is an important mechanism of energy metabolism for sheep under extreme hypoxic conditions. The dysregulation of genes in these pathways indicated that hypoxia-induced factors, angiogenesis, and glycolysis metabolism were the most important factors that allowed sheep to manage extreme hypoxic environmental pressure.

We also found the genes CYP2C31, CYP2B4, CYP2B5, and CYCS were functionally involved in oxygen binding, oxygen transport, and heme binding. In humans, indirect evidence suggests that hypoxia reduces the rate of biotransformation of drugs cleared by cytochrome P450 subfamilies $C Y P 1 A, 2 B$, and $2 C$. Fradette et al found that hypoxia down-regulates rabbit hepatic CYP1A1, 1A2, 2B4, 2C5, and $2 C 16$ and up-regulates CYP3A6. CYP3A11 and P-glycoprotein were up-regulated in the livers of hypoxic rats [55]. In addition, the genes (TUBB4B, PSMD13, COL3A1, 
COL 1A2, DSG3, and ATP6) were also identified as candidate genes associated with high altitude adaptation by previous functional studies. Kharrati-Koopaee et a/ found that PSMD13 gene was associated with the hypoxia by whole genome sequencing of lowland and highland chickens [26]. Qi et al conducted a cross-tissue, cross-altitude, and cross-species study to characterize the transcriptomic landscape of domestic yaks. They found that lung and heart are two key organs showing adaptive transcriptional changes, five of collagen genes (COL 1A2, COL $3 A 1$, COL5A2, COL 14A1, and COL 15A1) highlighting the crucial role of collagen involved pathways in high altitude adaptation [27]. The previous exome sequencing of five Chinese cashmere goat breeds revealed a candidate gene, $D S G 3$, responsible for the high altitude adaptation of the Tibetan goat. And the mutations significantly segregated high- and low-altitude goats in two clusters, indicating the contribution of DSG3 to the high altitude hypoxia adaptation in the Tibetan goat [29]. Wang et al sequenced the ATP8 and ATP6 genes in 66 Tibetan yaks and 81 domestic cattle found that haplotypes $\mathrm{H} 4$ in ATP8 and H5 in ATP6 present only in Tibetan yaks were suggested to be positively associated with high altitude adaptation [30].

Overall, the expression profile of IncRNAs and mRNAs in liver and lung tissue based on the comparative transcriptome analysis between high- and low- altitude sheep indicate that lung and liver are two key organs showing adaptive transcriptional changes. Moreover, the candidate genes involved in HIF-1,VEGF, and glycolysis/gluconeogenesis pathways, as well as oxygen binding, oxygen transport, and heme binding molecular function that were putatively associated with hypoxia responses at high altitudes were screened. These findings, in combination with the results of physiological and biochemical indices analysis, are valuable to understanding the genetic mechanism of hypoxic adaptation in sheep.

\section{Conclusions}

In summary, we demonstrated the expression profiles of mRNAs and IncRNAs in Tibetan sheep and Hu sheep in order to understand their regulatory roles in Tibetan sheep adaption to high altitude hypoxia environment. A collection of aberrantly expressed IncRNA, a set of target genes and biological pathways known to be relevant for altitude adaptation were identified by comparative transcriptome analysis between Tibetan sheep and Hu sheep. Our study might contribute to find out the core DE IncRNAs between Tibetan sheep and Hu sheep. In addition, further study of these IncRNAs could provide useful insights into the genetic regulation mechanism of IncRNAs in Tibetan sheep adaption to high altitude hypoxia environment.

\section{Methods}

\section{Ethics statement}

All the experimental procedures related to animals were carried out according to the guidelines for the care and use of experimental animals established by the Ministry of Agriculture of People's Republic of China. All experiments on animals were conducted under a permit (Approval No. NKMYD201805; dated: 18 October 2018) approved by the ethics committee of Lanzhou Institute of Husbandry and Pharmaceutical Sciences of Chinese Academy of Agricultural Sciences (LIHPS, CAAS).

\section{Animal sample preparation}

Five sheep (Ovis aries) populations, including Huoba (HB, altitude $4468 \mathrm{~m}$ ), Awang (AW, altitude $4452 \mathrm{~m}$ ), Ganjia (GJ, altitude $3851 \mathrm{~m}$ ) and Qilian (WT, altitude $3621 \mathrm{~m}$ ) Tibetan sheep on the Qinghai-Tibet Plateau and Hu sheep (HS, altitude $-67 \mathrm{~m}$ ) were obtained from individual farmers in this study. All the experimental sheep were raised 
under an environment with natural light and free access to food and water. The adult individuals (ewes, aged 3 4 years) within each population were randomly selected for this study. More than five sheep within each population were used for physiological and biochemical characteristics analyses. All experimental animals were anesthetized by pentobarbital sodium, and then were put to death after bloodletting. Three sheep within each population were selected to obtain the liver and lung samples for transcriptome analysis (Table 2), and all the samples were immediately snap-frozen in liquid nitrogen for total RNA extraction.

\section{Physiological and biochemical measurement}

To observe the changes of related blood physiological and biochemical parameters under hypoxia at high altitude in sheep, we sampled Tibetan sheep and Hu sheep from different altitudes. Jugular venous blood samples from $3 \sim$ 4 years adult sheep that lived at different altitudes as described in Table 2 were collected to measure the haematological parameters: RBC, WBC, HGB and others using a HC-3000 Auto Hematology Analyzer (Jinan Meiyyilin Electronic Instrument Co., Ltd, Jinan, China China). Moreover, the blood gas indices including partial pressure of carbon dioxide $\left(\mathrm{PCO}_{2}\right), \mathrm{PO}_{2}, \mathrm{O}_{2} \mathrm{~S}$, SBE and others were repeatedly measured on an IL $1302 \mathrm{pH} / \mathrm{Blood}$ Gas Analyzer (Instrumentation Laboratories, MA). For the analysis of blood biochemical indices, the blood samples were centrifuged at $3000 \mathrm{~g}$ for $10 \mathrm{~min}$, after which the supernatant was collected, the serum biochemical parameters: ALT, AST, TP, PCHE and others were analyzed with a Dirui CS-600 automatic biochemical analyzer (Dirui Industrial Co., Ltd; Changchun, China).

After euthanasia, lung organ was taken out immediately and excised into 7 pieces tissue from the same part of the left lung of each sheep. The lungs were washed with $0.9 \%$ saline, and then fixed with Bouin's solution containing $75 \mathrm{~mL}$ saturated picric acid solution, $25 \mathrm{~mL}$ formaldehyde, and $5 \mathrm{~mL}$ glacial acetic acid for $48 \mathrm{~h}$ at room temperature. Next, the tissues were embedded in paraffin and 4- $\mu \mathrm{m}$-thick sections were made for hematoxylin-eosin (HE) staining. The morphology of lung tissues was observed under a virtual microscope (Olympus, BX51, Japan) [43].

\section{RNA isolation, library construction and sequencing}

Total RNA was extracted using TRIzol® Reagent (Life Technologies) according to the manufacturer's protocol. RNA degradation and contamination, especially DNA contamination, was monitored on $1.5 \%$ agarose gels. RNA concentration and purity were measured using the NanoDrop 2000 Spectrophotometer (Thermo Fisher Scientific, Wilmington, DE). RNA integrity was assessed using the RNA Nano 6000 Assay Kit of the Agilent Bioanalyzer 2100 System (Agilent Technologies, CA, USA).

A total amount of $1.5 \mu \mathrm{g}$ RNA per sample was used as input material for rRNA removal using the Ribo-Zero rRNA Removal Kit (Epicentre, Madison, WI, USA). Sequencing libraries were generated using NEBNext R UltraTM Directional RNA Library Prep Kit for Illumina R (NEB, USA) following manufacturer's recommendations and index codes were added to attribute sequences to each sample. Briefly, Fragmentation was carried out using divalent cations under elevated temperature in NEBNext First Strand Synthesis Reaction Buffer (5X). First strand cDNA was synthesized using random hexamer primer and reverse transcriptase. Second-strand cDNA synthesis was subsequently performed using DNA Polymerase I and RNase H. Remaining overhangs were converted into blunt ends via exonuclease/polymerase activities. After adenylation of 3' ends of DNA fragments, NEBNext Adaptor with hairpin loop structure was ligated to prepare hybridization. In order to select insert fragments of preferentially 150 200 bp in length, the library fragments were purified with AMPure XP Beads (Beckman Coulter, Beverly, USA). Then $3 \mu$ I USER Enzyme (NEB, USA) was used with size-selected, adaptor-ligated cDNA at $37^{\circ} \mathrm{C}$ for 15 min before PCR. 
Then PCR was performed with Phusion High-Fidelity DNA polymerase, Universal PCR primers and Index(X) Primer. At last, PCR products were purified (AMPure XP system) and library quality was assessed on the Agilent Bioanalyzer 2100 and qPCR [56]. The libraries were sequenced on an Illumina Hiseq 2500 platform (Illumina Inc., San Diego, CA, USA) according to the manufacturer's instructions and 125 bp paired-end reads were generated.

\section{Quality control and RNA-seq data analysis}

Raw data (raw reads) of fastq format were firstly processed through in-house perl scripts. In this step, clean data (clean reads) were obtained by removing reads containing adapter, reads containing poly-N and low-quality reads from raw data. At the same time, Q20, Q30, GC-content and sequence duplication level of the clean data were calculated. All the downstream analyses were based on clean data with high quality $[57,58]$. The clean reads were aligned to the genome using TopHat version 2.0.9. Mapped reads from TopHat for each sample were assembled using Cufflinks vision 2.1.1. The multiple assembled transcript files (GTF format) for different samples were then merged together to produce a unique transcriptome set using the Cuffmerge utility provided by Cufflinks package.

\section{LncRNA analysis and quantification of gene expression levels}

The transcriptome was assembled using the Cufflinks and Scripture based on the reads mapped to the reference genome. The assembled transcripts were annotated using the Cuffcompare program from the Cufflinks package. The unknown transcripts were used to screen for putative IncRNAs. Four computational approaches including CPC/ $\mathrm{CNCl} / \mathrm{CPAT}$ / Pfam were combined to sort non-protein-coding RNA candidates from putative protein-coding RNAs in the unknown transcripts. Putative protein-coding RNAs were filtered out using a minimum length and exon number threshold. Transcripts with lengths more than $200 \mathrm{nt}$ and have more than two exons were selected as IncRNA candidates and further screened using CPC/ CNCl/ CPAT/ Pfam that has the power to distinguish the protein-coding genes from the non-coding genes. As well as the different types of IncRNAs including lincRNA, intronic IncRNA, antisense IncRNA were selected using cuffcompare.

Cuffdiff (v2.1.1) was used to calculate fragments per kilo-base of exon per million fragments mapped (FPKMs) of both IncRNAs and coding genes in each sample [59]. Gene FPKMs were computed by summing the FPKMs of transcripts in each gene group based on the length of the fragments and reads count mapped to this fragment.

\section{Differential expression analysis}

Differential expression analysis of five groups was performed using the DESeq R package (1.10.1). DESeq provides statistical routines for determining differential expression in digital gene expression data using a model based on the negative binomial distribution. The resulting $P$-values were adjusted using Benjamini and Hochberg's approach for controlling the false discovery rate. Genes with an adjusted $P$-value $<0.01$ and absolute value of log2 (Fold change) $>1$ found by DESeq were assigned as differentially expressed.

\section{Prediction of potential target genes of IncRNAs}

To explore the roles of IncRNA in Tibetan sheep adaption to hypoxia at high altitude, IncRNA-targeted genes were predicted based on cis and trans principle. Cis action indicated a positional relationship, representing a gene located within the range of $100 \mathrm{~kb}$ from the IncRNA. Trans action meant that there were complementary sequences between the mRNA and IncRNA; the sequences of mRNAs that overlapped with IncRNAs were predicted by LncTar software [60]. These two interaction mechanisms were considered preferential for the prediction of IncRNA-targeted genes.

\section{Functional enrichment analysis}


Gene functional enrichment analysis included Nr (NCBI non redundant protein sequences), COG (clusters of orthologous groups of proteins), Swiss-Prot (a manually annotated and reviewed protein sequence database), GO (Gene Ontology; http://www.geneontology.org/), and KEGG (Kyoto Encyclopedia of Genes and Genomes [61], which were utilized for screening genes related to highland hypoxia. GO enrichment analysis of the differentially expressed genes was implemented by the topGO R packages. KOBAS software [62] was used to test the statistical enrichment of DEGs in KEGG pathways.

\section{Interaction Network Construction}

Protein-protein interaction analysis of DEGs was based on the commonly used STRING database [63]. Briefly, the sequences of differentially expressed IncRNA targets were blasted (blastx) to Ovis aries genome to predict proteinprotein interactions using the STRING database. Then, the mRNA-mRNA and IncRNA-mRNA interaction networks were visualized by using Cytoscape version 3.5.1 [64].

\section{Quantitative Real-Time PCR (qRT-PCR) Validation}

Several DE IncRNAs, target genes and mRNAs putatively associated with hypoxia responses at high altitudes were selected and confirmed by qRT-PCR with GAPDH used as an internal reference. The primers used for qRT-PCR are

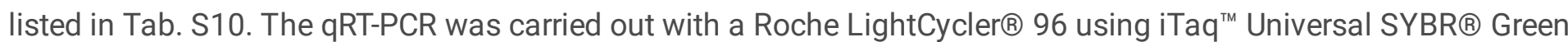
Supermix (Bio-Rad, United States). Each real-time RT-PCR reaction (in $25 \mu \mathrm{L}$ ) involved $12.5 \mu \mathrm{L} 2 \times$ SYBR Green Realtime PCR Master Mix (TaKaRa, Dalian), $1 \mu \mathrm{L}$ of each primer, $2 \mu \mathrm{L}$ cDNA and $8.5 \mu \mathrm{L} \mathrm{H}_{2} \mathrm{O}$. The amplification procedures were $95{ }^{\circ} \mathrm{C}$ for 5 min initially, followed by 45 cycles of $95^{\circ} \mathrm{C}$ for $15 \mathrm{~s}$ and $60{ }^{\circ} \mathrm{C}$ for 1 min. Quantification of mRNAs and IncRNAs was performed using the standard curve method with average cycle thresholds (Ct). The qRT-PCR data were generated from three independent samples per group. The correlation between the results of RNA-seq and qPCR was calculated using a correlation test.

\section{Statistical analysis}

All data was presented as the mean \pm SD. The Statistical Program for Social Sciences (SPSS) 20.0 software was employed to perform all of the statistical analyses. The multi-group comparisons of the means were analyzed using one-way analysis of variance. Statistically significant differences were determined at $p$-value $<0.05$.

/div>

\section{Abbreviations}

LncRNA『Long non-coding RNA; DEG: Differentially expressed genes; GO: Gene Ontology; KEGG: Kyoto Encyclopedia of Genes and Genomes; FPKM: Fragments per kilo-base of exon per million fragments mapped; qRT-PCR: Quantitative Real-Time PCR; VEGF: Vascular endothelial growth factor; HIF-1: Hypoxia inducible factor-1

\section{Declarations}

\section{Ethics approval and consent to participate}

We have obtained written informed consent to use the animals in this study from the owners of the animals and all experiments on animals were conducted under a permit (Approval No. NKMYD201805; dated: 18 October 2018) approved by the ethics committee of Lanzhou Institute of Husbandry and Pharmaceutical Sciences of Chinese Academy of Agricultural Sciences (LIHPS, CAAS).

\section{Consent for publication}


Not applicable.

\section{Availability of data and materials}

The datasets generated and/or analyzed during the current study are included in this published article and its supplementary information files. Genomic resources Oar_v3.1 for Ovis aries are available from Ensembl ( //ftp.ensembl.org/pub/release-78/fasta/ovis_aries/).

\section{Competing interests}

No competing interests were declared.

\section{Funding}

This work was financial supported by the National Natural Science Foundation for General Program of China (Grant No. 31872981), the National Key Research and Development Program of China (Grant No. 2018YFD0502100), the Agricultural Science and Technology Innovation Program of China (Grant no. CAAS-ASTIP-2015-LIHPS), the Modern China Wool Cashmere Technology Research System (Grant no. CARS-39-02), the Selection of Scientific Research Topics for Significant Production of the Chinese Academy of Agricultural Sciences (CAAS-ZDXT2018006), the Modern Agricultural Technology Research System of Gansu (Grant no. GARS08)『and the Central Level of Scientific Research Institutes for Basic R \& D Special Fund Business (Grant no. 1610322020004). These agencies played no role in either the design of the study, the collection, analysis, and interpretation of the data, or the writing of the manuscript.

\section{Author Contributions}

B.Y. and J. L. planned and designed the research. J.L. reviewed and revised the article. D.Z., D.Q., Z.Z. and Z.H. contributed to sample collection, performed experiments and data collection. C.Y. and Z. L. analyzed the data, interpreted results, and wrote the manuscript. T.G., J.Z. and D.Q. provided suggestions in drafting the manuscript and edited the manuscript. All authors have read and agreed to the published version of the manuscript.

\section{Acknowledgments}

The authors would like to thank manuscript reviewers on their comments and suggestions.

\section{References}

1. Yang XJ, Zhao YZ: Review on the genetic diversity of tibet sheep. J Gansu Agric Univ. 2002, 37(4):395-400.

2. Yang C, Gao P, Hou F, Yan T, Chang S, Chen X, Wang Z: Relationship between chemical composition of native forage and nutrient digestibility by Tibetan sheep on the Qinghai-Tibetan Plateau. J Anim Sci. 2018, 96(3):1140-1149.

3. Pagani L, Ayub Q, Macarthur DG, Xue Y, Baillie JK, Chen Y, Kozarewa I, Turner DJ, Tofanelli S, Bulayeva K: High altitude adaptation in Daghestani populations from the Caucasus. Hum. Genet. 2012, 131(3):423-433.

4. Cheviron ZA, Brumfield RT: Genomic insights into adaptation to high-altitude environments. Heredity 2012, 108(4):354-361.

5. Sasaki R, Masuda S, Nagao M: Erythropoietin: Multiple Physiological Functions and Regulation of Biosynthesis. Biosci Biotechnol Biochem. 2014, 64(9):1775-1793. 
6. Salhan AK, Sharma SK, Chauhan S, Oza M: Improved Habitability Under Extreme Environments at High Attitude. Tanslational Research in Environmental and Occupational Stress, Singh, S.B.; Prabhakar, N.R.; Pentyala, S.N.; Eds. Springer India: New Delhi, India, 2014, pp.193-204, eBook ISBN 978-81-322-1928-6.

7. Wang XX, Zhang ZX, Yang WW, Zhang EF, Shao T, Hou LC: The Research Progress of Clinical Application of High Oxygen. Prog Mod Biomed. 2014, 14:2586-2589.

8. Shi H, Liu K: Cerebral tissue oxygenation and oxidative brain injury during ischemia and reperfusion. Front Biosci. 2007, 12(4):1318-1328.

9. Hochachka PW, Rupert JL, Monge C: Adaptation and conservation of physiological systems in the evolution of human hypoxia tolerance. Comp. Biochem. Physiol., Part A: Mol. Integr. Physiol. 1999, 124(1):1-17.

10. Semenza GL: HIF-1 and mechanisms of hypoxia sensing. Curr Opin Cell Biol. 2001, 13(2):167-171.

11. Wang GL, Jiang BH, Rue EA, Semenza GL: Hypoxia-inducible factor 1 is a basic-helix-loop-helix-PAS heterodimer regulated by cellular 02 tension. Proc Natl Acad Sci. USA. 1995, 92(12):P.5510-5514.

12. Zhang $P$, Zhang $X$, Hao X, Wang Y, Hui Y, Wang H, Hu D, Zhou J: Rac1 activates HIF-1 in retinal pigment epithelium cells under hypoxia. Graefes Arch Clin Exp Ophthalmol. 2009, 247(5):633-639.

13. Zhang F, Wu W, Deng Z, Zheng X, Wang X: High altitude increases the expression of hypoxia-inducible factor 1a and inducible nitric oxide synthase with intest-inal mucosal barrier failure in rats. In. J Clin Exp. Pathol. 2015, 8(5):5189-5195.

14. Saldana MJ, Salem LE, Travezan R: High altitude hypoxia and chemodectomas. Hum Pathol 1973, 4(2):251263.

15. Kornienko AE, Guenzl PM, Barlow DP, Pauler FM: Gene regulation by the act of long non-coding RNA transcription. BMC Bio/ 2013, 11:59-59.

16. Li W, Li J, Wang R, Xie H, Jia Z: MDR1 will play a key role in pharmacokinetic changes under hypoxia at high altitude and its potential regulatory networks. Drug Metabolism Reviews 2015, 47(2):191-198.

17. Shang P, Li W, Liu G, Zhang J, Li M, Wu L, Wang K, Chamba Y: Identification of IncRNAs and Genes Responsible for Fatness and Fatty Acid Composition Traits between the Tibetan and Yorkshire Pigs. Int J Genomics 2019, 2019:5070975.

18. He X, Zheng J, He Y, Wang Y, Wang L, Bai M, Jin T, Yuan D: Long Non-coding RNA LINC-PINT and LINC00599 Polymorphisms are Associated With High-altitude Pulmonary Edema in Chinese. Arch Bronconeumol 2020, 56(6):360-364.

19. Ge RL, Chen QH, Wang LH, Gen D, Yang P, Kubo K, Fujimoto K, Matsuzawa Y, Yoshimura K, Takeoka M: Higher exercise performance and lower V02max in Tibetan than Han residents at 4,700 m altitude. J Appl Physiol. 1994, 77(2):684-691.

20. Han S. X GX, Yang S. L.,: Physiologic and Molecular Mchanism of the Animal Hypoxia Adaptation. Chinese animal husbandry and veterinary medicine 2010, 37(8):29-34.

21. Frede S, Fandrey J: Cellular and Molecular Defenses Against Hypoxia. In: High Altitude: Human Adaptation to Hypoxia. Edited by Swenson ER, Bärtsch P. New York, NY: Springer New York; 2014: 23-35.

22. Simonson TS, Yang Y, Huff CD, Yun H, Qin G, Witherspoon DJ, Bai Z, Lorenzo FR, Xing J, Jorde LB et al: Genetic evidence for high-altitude adaptation in Tibet. Science 2010, 329(5987):72-75.

23. Feng CC, Lin CC, Lai YP, Chen TS, Asokan SM, Lin JY, Lin KH, Viswanadha VP, Kuo WW, Huang CY: Hypoxia suppresses myocardial survival pathway through HIF-1a-IGFBP-3-dependent signaling and enhances 
cardiomyocyte autophagic and apoptotic effects mainly via Fox03a-induced BNIP3 expression. Growth Factors 2016, 34:73-86.

24. Sakamoto T, Weng JS, Hara T, Yoshino S, Kozukahata H, Oyama M, Seiki M: Hypoxia-Inducible Factor 1 Regulation through Cross Talk between mTOR and MT1-MMP. Mol Cell Biol. 2014, 34(1):30-42.

25. Capitanio D, Fania C, Torretta E, Vigano A, Moriggi M, Bravata V, Caretti A, Levett DZH, Grocott MPW, Samaja M: TCA cycle rewiring fosters metabolic adaptation to oxygen restriction in skeletal muscle from rodents and humans. Sci Rep. 2017, 7(1):9723-9723.

26. Kharrati-Koopaee H, Ebrahimie E, Dadpasand M, Niazi A, Esmailizadeh A: Genomic analysis reveals variant association with high altitude adaptation in native chickens. Sci Rep. 2019, 9:9224.

27. Qi X, Zhang Q, He Y, Yang L, Zhang X: The Transcriptomic Landscape of Yaks Reveals Molecular Pathways for High Altitude Adaptation. Genome Bio Evol. 2019, 11(1):72-85.

28. Guo J, Zhong J, Li L, Zhong T, Wang L, Song T, Zhang H: Comparative genome analyses reveal the unique genetic composition and selection signals underlying the phenotypic characteristics of three Chinese domestic goat breeds. Genet Sel Evol. 2019, 51(1):1-18.

29. Kumar C, Song S, Jiang L, He X, Zhao Q, Pu Y, Malhi KK, Kamboh AA, Ma Y: Sequence Characterization of DSG3 Gene to Know Its Role in High-Altitude Hypoxia Adaptation in the Chinese Cashmere Goat. Front Genet. 2018, 9:553.

30. Wang J, Shi Y, Mauricio AE, Dang S, Jia X, Lai S: Genetic diversity of ATP8 and ATP6 genes is associated with high-altitude adaptation in yak. Mitochondrial Dna Part A 2018, 29(3):385-393.

31. Ishizaki T, Sakai A, Koizumi T, Ruan Z, Zhan GW: Blunted effect of the Kv channel inhibitor on pulmonary circulation in Tibetan sheep: A model for studying hypoxia and pulmonary artery pressure regulation. Respirology 2004, 9(1):125-129.

32. Rong C, Yan M, Zhen-Zhong B, Ying-Zhong Y, Dian-Xiang L, Qi-Sheng M, Qing G, Yin L, Ge RL: Cardiac adaptive mechanisms of Tibetan antelope (<i>Pantholops hodgsonii</i>) at high altitudes. Am J Vet Res. 2012, 73(6):809-813.

33. Liu FY, Chen QH: Effect of acute hypoxia on the parameters of blood gas in Tibetan plateau sheep. Chin $\mathrm{J}$ Zool. 2006, 41(1):48-52.

34. Ruan Z, Koizumi T, Sakai A, Ishizaki T, Wang Z: Endogenous nitric oxide and pulmonary circulation response to hypoxia in high-altitude adapted Tibetan sheep. Eur J App/ Physiol. 2004, 93(1-2):190-195.

35. Wang XR, Wu JP: Study on structural features of the cerebral arterial system associated with plateau adaptability in tibetan sheet. Acta Ecologiae Animalis Domastici 2013, 34(8).

36. Yuan LG, Sun Y, Huang BM: Micromorphological characteristics of the adult tibetan plateau sheep spermatic cord. Acta Veterinaria et Zootechnica Sinica 2011, 42(10):1450-1456.

37. Kopp F, Mendell JT: Functional Classification and Experimental Dissection of Long Noncoding RNAs. Cell 2018, 172(3):393-407.

38. Chen X, Yan GY: Novel human IncRNA-disease association inference based on IncRNA expression profiles. Bioinformatics 2013, 29(20):2617-2624.

39. Cao M, Zhao J, Hu G: Genome-wide methods for investigating long noncoding RNAs. Biomed. Pharmacother. 2019, 111:395-401.

40. Bakhtiarizadeh MR, Salami SA: Identification and Expression Analysis of Long Noncoding RNAs in Fat-Tail of Sheep Breeds. G3: Genes, Genomes, Genet. 2019, 9(4):1263-1276. 
41. Ren C, Deng M, Fan Y, Yang H, Zhang G, Feng X, Li F, Wang D, Wang F, Zhang Y: Genome-Wide Analysis Reveals Extensive Changes in LncRNAs during Skeletal Muscle Development in Hu Sheep. Genes (Basel) 2017, 8(8).

42. Feng X, Li F, Wang F, Zhang G, Pang J, Ren C, Zhang T, Yang H, Wang Z, Zhang Y: Genome-wide differential expression profiling of mRNAs and IncRNAs associated with prolificacy in Hu sheep. Biosci Rep. 2018, 38:BSR20171350.

43. Yang H, Wang F, Li F, Ren C, Pang J, Wan Y, Wang Z, Feng X, Zhang Y: Comprehensive analysis of long noncoding RNA and mRNA expression patterns in sheep testicular maturation. Biol Reprod. 2018, 99(3):650661.

44. Rayner BS, Hua S, Sabaretnam T, Witting PK: Nitric oxide stimulates myoglobin gene and protein expression in vascular smooth muscle. Biochem J. 2009, 423(2):169.

45. Mccurdy CE, Schenk S, Holliday MJ, Philp A, Houck JA, Patsouris D, Maclean PS, Majka SM, Klemm DJ, Friedman JE: Attenuated Pik3r1 Expression Prevents Insulin Resistance and Adipose Tissue Macrophage Accumulation in Diet-Induced Obese Mice. Diabetes 2012, 61(10):2495-2505.

46. Vorrink SU, Severson PL, Kulak MV, Futscher BW, Domann FE: Hypoxia perturbs aryl hydrocarbon receptor signaling and CYP1A1 expression induced by PCB 126 in human skin and liver-derived cell lines. Toxicol. Appl. Pharmacol. 2014, 274(3):408-416.

47. Moore, A.D. Thesis, A Study of effects on MMP14 transcriptional regulation and angiogenesis by hypoxia and statins. Ph.D, Queen Mary, University of London, 2014.

48. Chen HJ, Li DY, Saldeen T, Mehta JL: TGF-b1 modulates NOS expression and phosphorylation of Akt/PKB in rat myocytes exposed to hypoxia-reoxygenation. Am J Physiol Heart Circ Physiol. 2001, 281(3):H1035-1039.

49. Yang J, Li WR, Lv FH, He SG, Tian SL, Peng WF, Sun YW, Zhao YX, Tu XL, Min Z: Whole-genome sequencing of native sheep provides insights into rapid adaptations to extreme environments. Mol Biol Evol. 2016, 33(10):2576-2592.

50. Wei C, Wang H, Liu G, Zhao F, Kijas JW, Ma Y, Lu J, Zhang L, Cao J, Wu M: Genome-wide analysis reveals adaptation to high altitudes in Tibetan sheep. Sci Rep. 2016, 6:26770.

51. Murakami A, Takahashi F, Nurwidya F, Kobayashi I, Minakata K, Hashimoto M, Nara T, Kato M, Tajima K, Shimada N: Hypoxia Increases Gefitinib-Resistant Lung Cancer Stem Cells through the Activation of Insulin-Like Growth Factor 1 Receptor. PloS One 2014, 9(1):e86459.

52. Mora, A.; Davies, A.M.; Bertrand, L.; Sharif, I.; Budas, G.R.; Jovanović, S.; Mouton, V.; Kahn,C.R.; Lucocq, J.M.; Gray, G.A.; Jovanović, A.; Alessi, D.R. Deficiency of PDK1 in cardiac muscle results in heart failure and increased sensitivity to hypoxia. EMBO J. 2014, 22, 4666-4676, doi: 10.1093/emboj/cdg469.

53. Jiang X, Zhang J, Xia M, Qiu W, Wang H, Zhao D, Wang Y: Role of activating transcription factor 3 (ATF3) in sublytic C5b-9-induced glomerular mesangial cell apoptosis. Cell Mol Immunol 2010, 7(2):143-151.

54. Parra V, Bravo-Sagua R, Norambuena-Soto I, Hernández-Fuentes CP, Castro PF: Inhibition of mitochondrial fission prevents hypoxia-induced metabolic shift and cellular proliferation of pulmonary arterial smooth muscle cells. Biochim Biophys Acta 2017, 1863(11):2891-2903.

55. Fradette C, Batonga J, Teng S, Piquettemiller M, Souich PD: Animal models of acute moderate hypoxia are associated with a down-regulation of CYP1A1, 1A2, 2B4, 2C5, and $2 \mathrm{C} 16$ and up-regulation of CYP3A6 and Pglycoprotein in liver. Drug Metab Dispos. 2007, 35(5):765.

56. Zuo J, Wang Y, Zhu B, Luo Y, Wang Q, Gao L: Analysis of the Coding and Non-Coding RNA Transcriptomes in Response to Bell Pepper Chilling. Int J Mol Sci. 2018, 19(7):2001-. 
57. Jiang F, Chen XP, Hu WS, Zheng SQ: Identification of differentially expressed genes implicated in peel color (red and green) of Dimocarpus confinis. Springerplus 2016, 5(1):1088.

58. Ai Y, Zhang Q, Wang W, Zhang C, Cao Z, Bao M, He Y: Transcriptomic Analysis of Differentially Expressed Genes during Flower Organ Development in Genetic Male Sterile and Male Fertile Tagetes erecta by Digital GeneExpression Profiling. PloS One 2016, 11(3):e0150892.

59. Trapnell C, Williams BA, Pertea G, Mortazavi A, Kwan G, van Baren MJ, Salzberg SL, Wold BJ, Pachter L: Transcript assembly and quantification by RNA-Seq reveals unannotated transcripts and isoform switching during cell differentiation. Nat biotechnol. 2010, 28(5):511-515.

60. Li J, Ma W, Zeng P, Wang J, Geng B, Yang J, Cui Q: LncTar: a tool for predicting the RNA targets of long noncoding RNAs. Brief Bioinform 2015, 16(5):806-812.

61. Huang DW, Sherman BT, Lempicki RA: Systematic and integrative analysis of large gene lists using DAVID bioinformatics resources. Nat Protoc. 2008, 4(1):44-57.

62. Mao X, Tao C, Olyarchuk JG, Wei L: Automated genome annotation and pathway identification using the KEGG Orthology (KO) as a controlled vocabulary. Bioinformatics 2005, 21(19):3787-3793.

63. Szklarczyk D, Morris JH, Cook H, Kuhn M, Wyder S, Simonovic M, Santos A, Doncheva NT, Roth A, Bork P et al: The STRING database in 2017: quality-controlled protein-protein association networks, made broadly accessible. Nucleic acids res. 2017, 45(D1):D362-D368.

64. Shannon P, Markiel A, Ozier O, Baliga NS, Wang JT, Ramage D, Amin N, Schwikowski B, Ideker T: Cytoscape: a software environment for integrated models of biomolecular interaction networks. Genome Res. 2003, 13(11):2498-2504.

\section{Tables}


Table 1

Sampling information of five sheep populations (Ovis aries) for transcriptome analysis

\begin{tabular}{|c|c|c|c|c|c|c|c|c|}
\hline Populations & $\begin{array}{l}\text { Population } \\
\text { code }\end{array}$ & $\begin{array}{l}\text { Sample } \\
\text { Size }\end{array}$ & Sex & $\begin{array}{l}\text { Longitude } \\
\text { and latitude }\end{array}$ & $\begin{array}{l}\text { Sampling } \\
\text { location }\end{array}$ & $\begin{array}{l}\text { Altitude } \\
\text { (m) }\end{array}$ & $\begin{array}{l}\text { Liver } \\
\text { sample } \\
\text { ID }\end{array}$ & $\begin{array}{l}\text { Lung } \\
\text { sample } \\
\text { ID }\end{array}$ \\
\hline \multirow{4}{*}{$\begin{array}{l}\text { Awang } \\
\text { Tibetan } \\
\text { sheep }\end{array}$} & \multirow[t]{4}{*}{ AW } & \multirow[t]{4}{*}{3} & \multirow[t]{4}{*}{ Male } & \multirow{4}{*}{$\begin{array}{l}\text { N:30³5'709" } \\
\text { E:098²7'755" }\end{array}$} & \multirow{4}{*}{$\begin{array}{l}\text { Ngawang } \\
\text { third village, } \\
\text { Awang } \\
\text { Town, } \\
\text { Gongjue } \\
\text { County, } \\
\text { Nyingchi } \\
\text { prefecture of } \\
\text { Tibet } \\
\text { Autonomous } \\
\text { Region }\end{array}$} & \multirow[t]{4}{*}{4452} & L01 & L16 \\
\hline & & & & & & & & \\
\hline & & & & & & & L02 & L17 \\
\hline & & & & & & & L03 & L18 \\
\hline \multirow{5}{*}{$\begin{array}{l}\text { Huoba } \\
\text { Tibetan } \\
\text { sheep }\end{array}$} & \multirow[t]{5}{*}{$\mathrm{HB}$} & \multirow[t]{5}{*}{3} & \multirow[t]{5}{*}{ Male } & \multirow{5}{*}{$\begin{array}{l}N: 30^{\circ} 10^{\prime} 47^{\prime \prime} \\
E: 083^{\circ} 10^{\prime} 09^{\prime \prime}\end{array}$} & \multirow{4}{*}{$\begin{array}{l}\text { Zazi village, } \\
\text { Horba } \\
\text { township, } \\
\text { Zhongba } \\
\text { County, } \\
\text { Shigatse } \\
\text { prefecture of } \\
\text { Tibet }\end{array}$} & \multirow[t]{5}{*}{4468} & L04 & L19 \\
\hline & & & & & & & & \\
\hline & & & & & & & L05 & L20 \\
\hline & & & & & & & L06 & L21 \\
\hline & & & & & $\begin{array}{l}\text { Autonomous } \\
\text { Region }\end{array}$ & & & \\
\hline \multirow{4}{*}{$\begin{array}{l}\text { Ganjia } \\
\text { Tibetan } \\
\text { sheep }\end{array}$} & \multirow[t]{4}{*}{ GJ } & \multirow[t]{4}{*}{3} & \multirow[t]{4}{*}{ Male } & \multirow{4}{*}{$\begin{array}{l}N: 35^{\circ} 21^{\prime} 017^{\prime \prime} \\
E: 102^{\circ} 30^{\prime} 009^{\prime \prime}\end{array}$} & \multirow{4}{*}{$\begin{array}{l}\text { Renqing } \\
\text { village, } \\
\text { Ganjia } \\
\text { Town, Xiahe } \\
\text { County, } \\
\text { Gannan } \\
\text { Tibetan } \\
\text { Autonomous } \\
\text { State, Gansu } \\
\text { Province }\end{array}$} & \multirow[t]{4}{*}{3851} & L10 & L22 \\
\hline & & & & & & & & \\
\hline & & & & & & & L11 & L23 \\
\hline & & & & & & & L12 & L24 \\
\hline \multirow{4}{*}{$\begin{array}{l}\text { Qilian White } \\
\text { Tibetan } \\
\text { sheep }\end{array}$} & \multirow[t]{4}{*}{ WT } & \multirow[t]{4}{*}{3} & \multirow[t]{4}{*}{ Male } & \multirow{4}{*}{$\begin{array}{l}N: 37^{\circ} 25^{\prime} 068^{\prime \prime} \\
E: 099^{\circ} 00^{\prime} 905^{\prime \prime}\end{array}$} & \multirow{4}{*}{$\begin{array}{l}\text { Awugeer } \\
\text { village, } \\
\text { Shengge } \\
\text { Town, Qilian } \\
\text { County, } \\
\text { Delingha } \\
\text { City, } \\
\text { Mongolian } \\
\text { Autonomous } \\
\text { State, } \\
\text { Qinghai } \\
\text { Province }\end{array}$} & \multirow[t]{4}{*}{3620} & L07 & L25 \\
\hline & & & & & & & & \\
\hline & & & & & & & L08 & L26 \\
\hline & & & & & & & L09 & L27 \\
\hline Hu sheep & HS & 3 & Male & $\mathrm{N}: 34^{\circ} 18^{\prime} 693^{\prime \prime}$ & No. 169 , & -67 & L13 & L28 \\
\hline
\end{tabular}




\begin{tabular}{|c|c|c|c|c|c|c|c|c|}
\hline Populations & $\begin{array}{l}\text { Population } \\
\text { code }\end{array}$ & $\begin{array}{l}\text { Sample } \\
\text { Size }\end{array}$ & Sex & $\begin{array}{l}\text { Longitude } \\
\text { and latitude }\end{array}$ & $\begin{array}{l}\text { Sampling } \\
\text { location }\end{array}$ & $\begin{array}{l}\text { Altitude } \\
\text { (m) }\end{array}$ & $\begin{array}{l}\text { Liver } \\
\text { sample } \\
\text { ID }\end{array}$ & $\begin{array}{l}\text { Lung } \\
\text { sample } \\
\text { ID }\end{array}$ \\
\hline & & & & \multirow[t]{2}{*}{$\mathrm{E}: 117^{\circ} 57^{\prime} 763^{\prime \prime}$} & \multirow{2}{*}{$\begin{array}{l}\text { guzi village, } \\
\text { zhaodun } \\
\text { town, pizhou } \\
\text { city, jiangsu } \\
\text { province }\end{array}$} & & L14 & L29 \\
\hline & & & & & & & L15 & L30 \\
\hline
\end{tabular}

Note: The number of altitude only refers to the value in sampling location, more animal samples from the same area were used for physiological and biochemical analysis. 
Table 2

The candidate genes putatively associated with the plateau adaptation of Tibetan sheep

\begin{tabular}{|c|c|c|}
\hline Gene ID & Gene symbol & Gene description \\
\hline ENSOARG00000006910 & MB & Oxygen binding \\
\hline ENSOARG00000005870 & PIK3R1 & HIF-1 signaling pathway \\
\hline ENSOARG00000007525 & IGF1R & HIF-1 signaling pathway \\
\hline ENSOARG00000018633 & PDK1 & HIF-1 signaling pathway \\
\hline ENSOARG00000000709 & CYP2C31 & heme binding \\
\hline ENSOARG00000007211 & CYP2B4 & heme binding \\
\hline ENSOARG00000007575 & CYP2B5 & heme binding \\
\hline ENSOARG00000007316 & CYP2B11 & heme binding \\
\hline ENSOARG00000012689 & CYP1A1 & heme binding \\
\hline ENSOARG00000025165 & CYCS & heme binding \\
\hline ENSOARG00000004175 & FZD6 & vascular endothelial growth factor \\
\hline ENSOARG00000008791 & IFNB2 & vascular endothelial growth factor \\
\hline ENSOARG00000010493 & ATF3 & Glycolysis/gluconeogenesis \\
\hline ENSOARG00000017498 & PPCK1 & Glycolysis/gluconeogenesis \\
\hline ENSOARG00000007023 & PFKFB2 & Glycolysis/gluconeogenesis \\
\hline ENSOARG00000001159 & MMP14 & response to stress \\
\hline ENSOARG00000007468 & TGFB1 & immune function \\
\hline ENSOARG00000002665 & TUBB4B & Cytoskeleton \\
\hline ENSOARG00000008674 & PSMD13 & proteasome regulatory particle \\
\hline ENSOARG00000002857 & COL3A1 & collagen involved pathways \\
\hline ENSOARG00000007594 & COL1A2 & collagen involved pathways \\
\hline ENSOARG00000006399 & DSG3 & keratinocyte adhesion in skin \\
\hline ENSOARG00000008745 & ATP6 & mitochondrial ATPase assembly \\
\hline
\end{tabular}



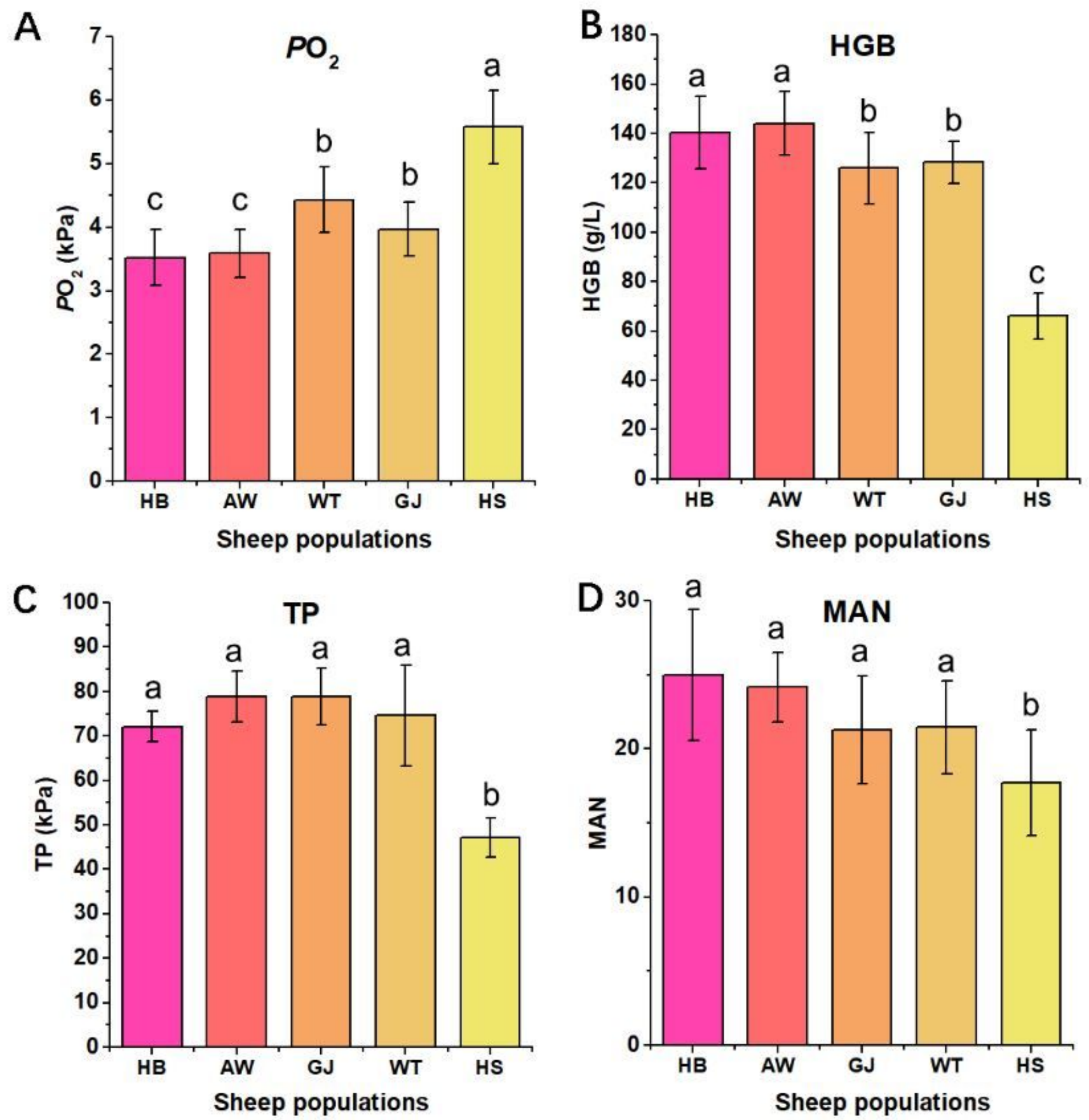

Figure 1

The physiological and biochemical indices of five sheep populations from different altitude. (A) Partial pressure of carbon dioxide (PO2). (B) Haemoglobin contents (HGB). (C) Total protein (TP). (D) The number of alveolar counted per unit area (MAN). The columns with different letters are significantly different at $\mathrm{P}<0.05$. 
A
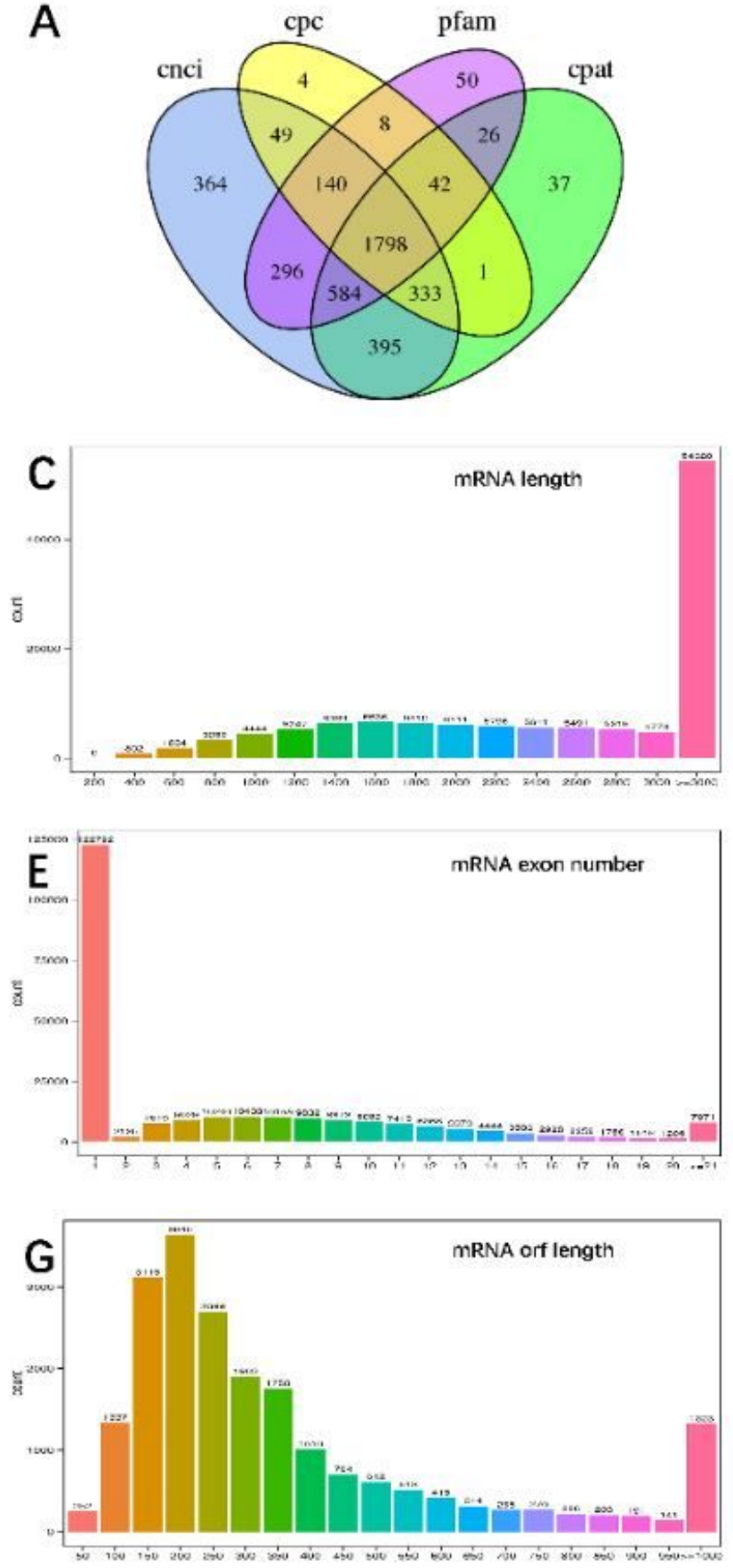

B
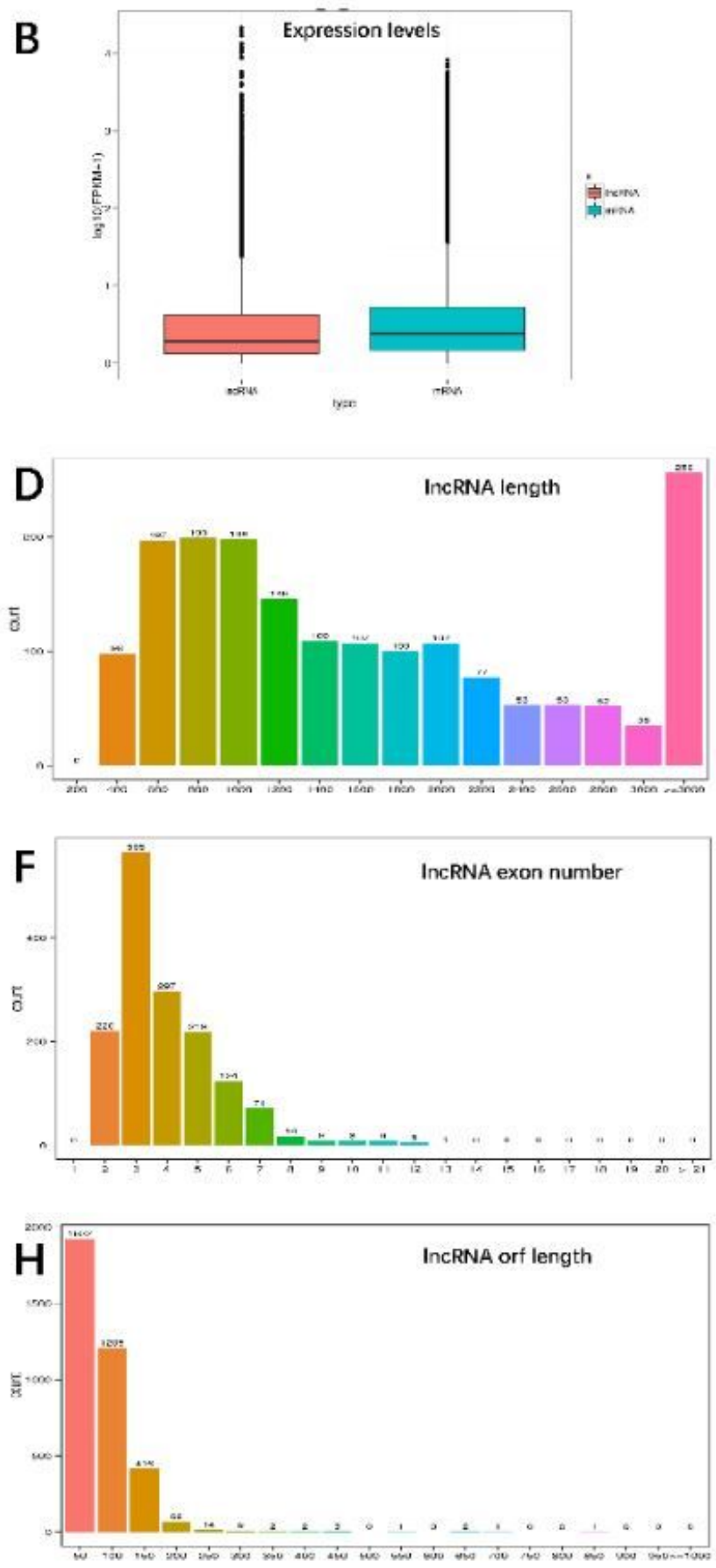

\section{Figure 2}

Identification of long non-coding RNAs (IncRNAs) and mRNAs involved in high altitude hypoxia adaptation in lung tissue. Coding potentiality filter using Coding Potential Calculator, Pfam, Phylogenetic codon substitution frequency, and Coding-Non-Coding Index (A). The boxplot shows the expression levels $(\log 10($ FPKM +1$))$ of IncRNAs and mRNAs (B). Transcript lengths distribution of mRNAs (C) and IncRNAs (D). Exon number distribution of mRNAs (E) and IncRNAs $(F)$. Open reading frame (ORF) length distribution of mRNAs $(\mathrm{G})$ and IncRNAs $(\mathrm{H})$. 

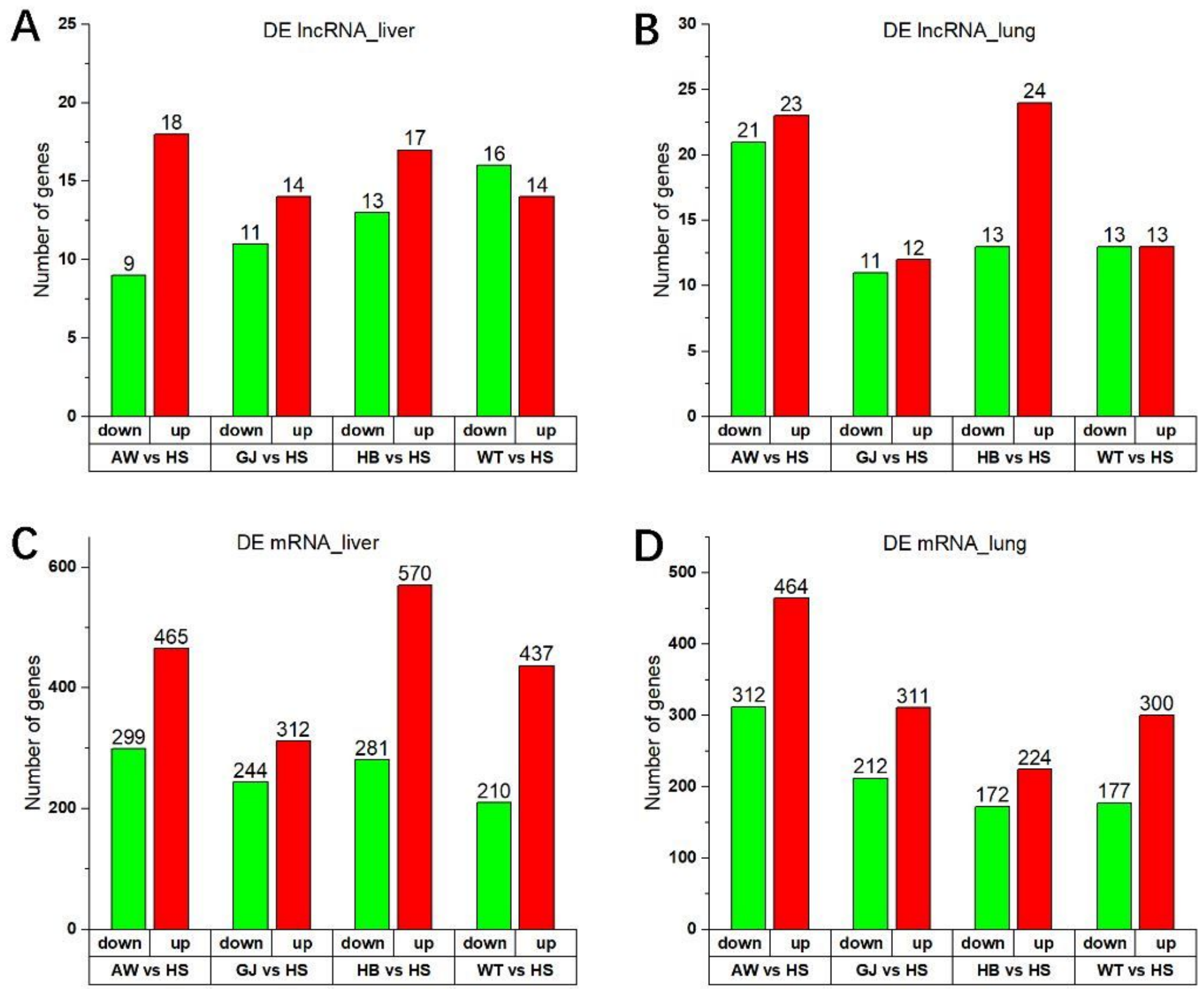

Figure 3

The up and down regulation of DE genes of five sheep populations. (A) Number of DE IncRNAs in liver samples. (B) Number of DE IncRNAs in lung samples. (C) Number of DE mRNAs in liver samples. (D) Number of DE mRNAs in lung samples. Red: up-regulated; Green: down-regulated. 


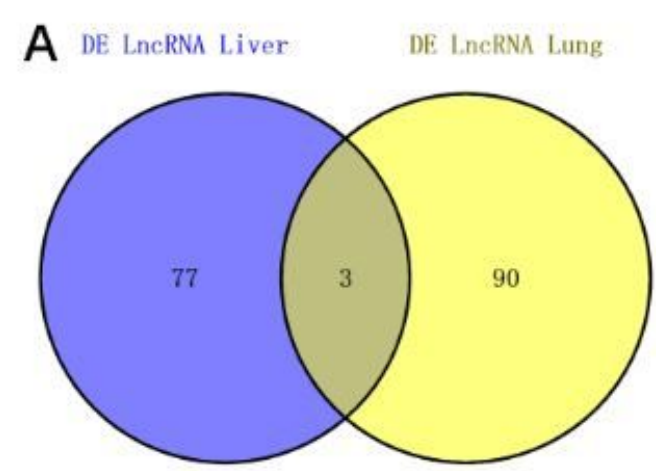

DE IncRNA

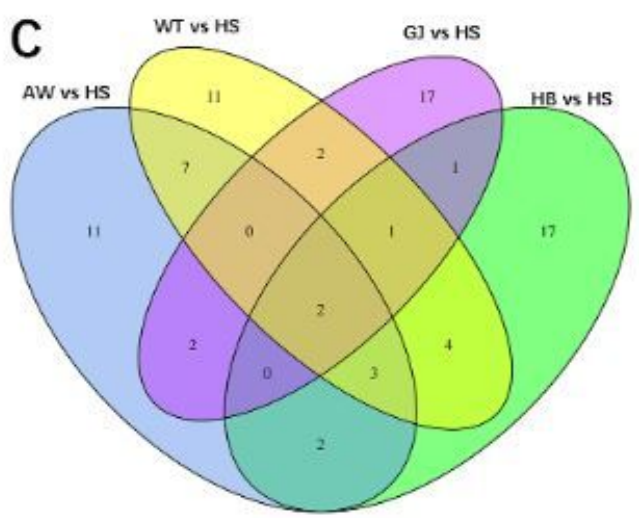

DE IncRNA_liver

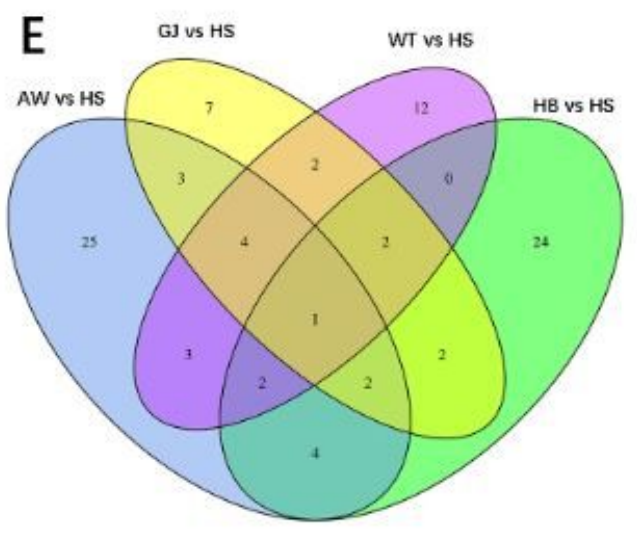

DE IncRNA_lung
B DE mRNA liver DE mRNA lung

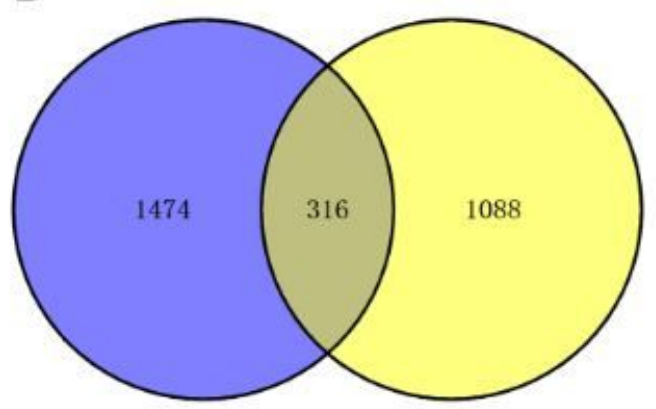

DE MRNA

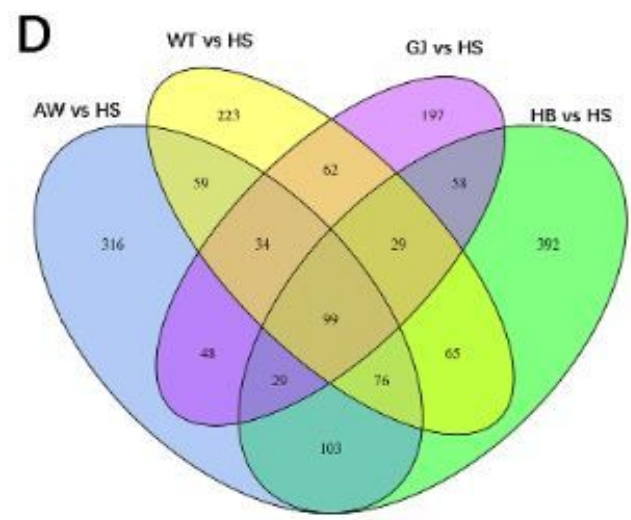

DE mRNA_liver

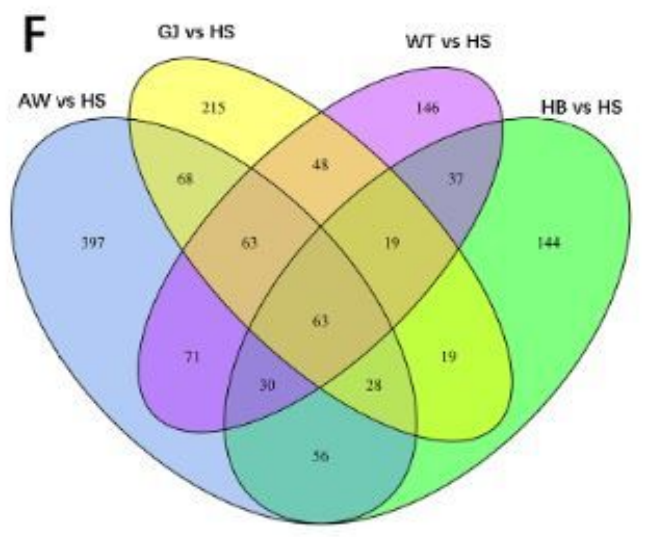

DE mRNA_lung

\section{Figure 4}

Venn diagram of common differential expression genes. (A) The common DE IncRNAs in pairwise comparison between lung and liver tissue. (B) The common DE mRNAs in pairwise comparison between lung and liver tissue. (C) The common DE IncRNAs in four comparison groups of liver samples (AW vs HS, HB vs HS, GJ vs HS, WT vs HS).

(D) The common DE mRNAs in four comparison groups of liver samples (AW vs HS, HB vs HS, GJ vs HS, WT vs HS).

(E) The common DE IncRNAs in four comparison groups of lung samples (AW vs HS, HB vs HS, GJ vs HS, WT vs HS). (F) The common DE mRNAs in four comparison groups of lung samples (AW vs HS, HB vs HS, GJ vs HS, WT vs $H S$ ). 

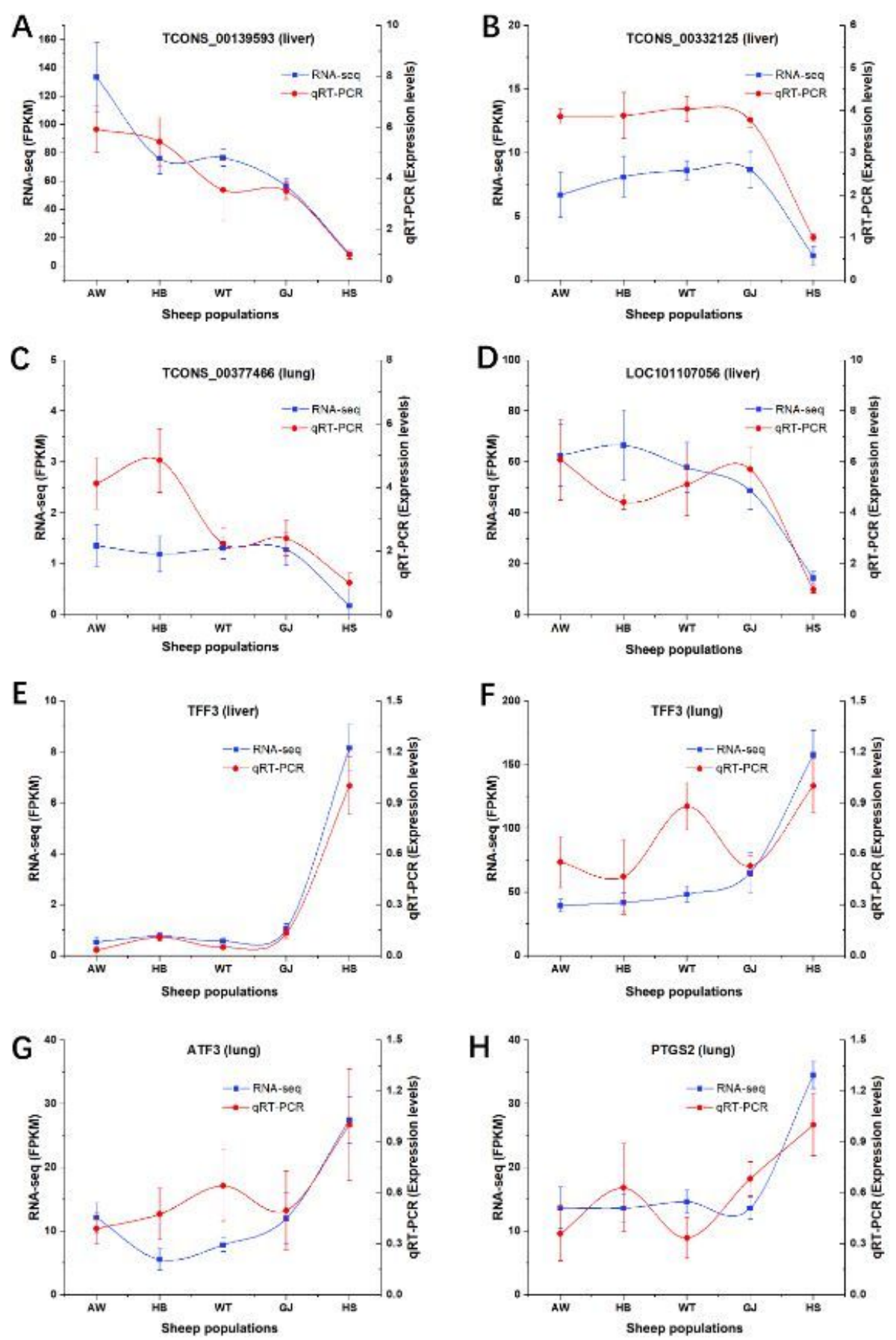

Figure 5

Confirmation of expression patterns of the eight selected differential expression genes using qRT-PCR. The trends of qRT-PCR results are consistent with RNA-seq data. (A) The common DE IncRNA TCONS_00139593 in five sheep populations of liver samples (AW, HB, GJ, WT, HS). (B) The common DE IncRNA TCONS_00332125 in five sheep populations of liver samples (AW, HB, GJ, WT, HS). (C) The common DE IncRNA TCONS_00377466 in five sheep populations of lung samples (AW, HB, GJ, WT, HS). (D) The common DE IncRNA TCONS_101107056 in five sheep populations of liver samples (AW, HB, GJ, WT, HS). (E) The common DE mRNAs TFF3 in five sheep populations of liver samples (AW, HB, GJ, WT, HS). (F) The common DE mRNAs TFF3 in five sheep populations of lung samples (AW, HB, GJ, WT, HS). (G) The common DE mRNAs ATF3 in five sheep populations of lung samples (AW, HB, GJ, WT, HS). (H) The common DE mRNAs PTGS2 in five sheep populations of lung samples (AW, HB, GJ, WT, HS). 


\section{Supplementary Files}

This is a list of supplementary files associated with this preprint. Click to download.

- Tables10.xlsx

- Tables9.xIsx

- Tables8.xisx

- Tables7.xIsx

- Tables6.xlsx

- Supplementaryinformation.docx

- Tables5.xIsx

- Tables4.xIsx

- Tables3.xisx

- Tables2.xlsx

- Tables1.xisx

- Figures4.tif

- FigureS3.tif

- Figures2.tif

- Figures1.tif 